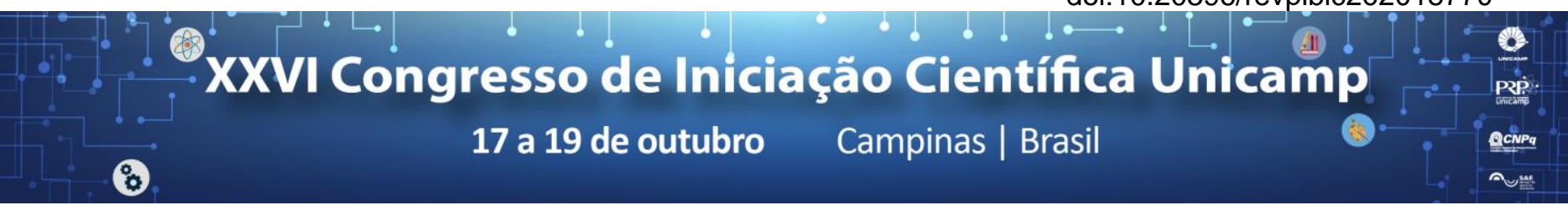

\title{
Determinação de cloro livre utilizando dispositivo microfluídico baseado em fibra têxtil.
}

\section{Laís de A. Pallos*, Aline G. Coelho, Dosil P. de Jesus.}

\section{Resumo}

Um dispositivo microfluídico usando fibra têxtil de algodão foi desenvolvido para a determinação de cloro livre através de detecção colorimétrica envolvendo reação iodométrica. O dispositivo se mostrou simples, de baixo custo e requer pequenos volumes de amostra e reagentes. Os dispositivos foram aplicados para a determinação de cloro livre em amostras de água de piscina e alvejante.

Palavras-chave: microfluídica, cloro livre, fibras têxteis.

\section{Introdução}

Os microdispositivos analíticos baseados em fibras têxteis ( $\mu$ TADs, do inglês Thread-based microfluidic analytical devices) se valem da hidrofilicidade e capacidade de transporte de soluções aquosas por filamentos e fibras têxteis. O uso dessas fibras como plataforma microfluídica apresenta vantagens como baixo custo, baixo consumo de amostra, alta resistência mecânica e flexibilidade da fibra, além da possibilidade de criação de estruturas 3D. ${ }^{1}$

Cloro é utilizado para eliminação de microrganismos patogênicos, principalmente em água para consumo humano e recreação. A determinação de cloro residual pode ser feita por vários métodos, sendo a reação colorimétrica com o N,N-dietil-p-fenilenediamina (DPD) a mais utilizada. ${ }^{2}$ Nesse trabalho foram utilizadas reações colorimétricas em $\mu \mathrm{TAD}$ com fibras de algodão para a determinação de cloro livre em amostras de alvejante e água de piscina.

\section{Resultados e Discussão}

Suportes para fixação das fibras foram fabricados em impressora 3D (modelo Sethi3D BB), empregando os polímeros ABS (acrilonitrilo-butadieno-estireno) e PETG (politereftalato de etileno glicol). Cinco nós consecutivos na mesma posição foram manualmente confeccionados em fibras de algodão. Esses nós tinham a função de aumentar a área da fibra para uma maior eficiência da mistura dos reagentes aplicados e possibilitar uma medida mais precisa da intensidade da cor desenvolvida após a reação. Após aplicação dos reagentes e analito, a área reacional foi fotografada (digitalizada) usando câmera de um telefone celular e a imagem era então tratada no software COREL PHOTO-PAINT®.

A reação com DPD foi testada, entretanto a coloração magenta desenvolvida na fibra era instável, desaparecendo rapidamente, o que dificultava a detecção e tratamento das imagens. Por isso, foi avaliada a clássica reação em que o cloro livre reage com íons iodeto $(0,2 \mathrm{~g} / \mathrm{mL})$, formando iodo, que na presença de amido $(10 \mathrm{~g} / \mathrm{L})$ produz uma coloração azul/roxa. A Figura 1 mostra imagens dos nós após adição dos reagentes e analitos.

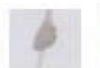

Branco $15 \quad 30$ $456075 \mathrm{mg} / \mathrm{L}$

Amostra água de piscina 1

Figura 1. Imagens da região dos nós após aplicação de reagentes e analitos.

A Figura 2 apresenta a curva analítica obtida com a medida de intensidade de cor em função da concentração de cloro livre. Os parâmetros analíticos estão indicados na Tabela 1. A Tabela 2 mostra as concentrações de cloro livre em diferentes amostras analisadas pelos métodos $\mu T A D$ e titulação iodométrica.

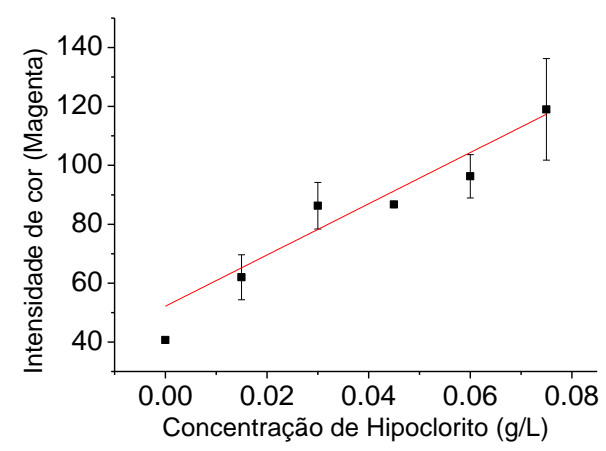

Figura 2. Curva analítica para a reação iodométrica usando $\mu \mathrm{TAD}$.

Tabela 1. Parâmetros analíticos do método $\mu$ TAD.

\begin{tabular}{|c|c|}
\hline Faixa da curva $(\mathrm{g} / \mathrm{L})$ & 0,015 a 0,075 \\
\hline $\mathrm{R}^{2}$ & 0,93 \\
\hline Equação da curva & $\mathrm{y}=52,16221+869,4289 \mathrm{x}$ \\
\hline $\mathrm{LOD}(\mathrm{g} / \mathrm{L})$ & 0,002 \\
\hline $\mathrm{LOQ}(\mathrm{g} / \mathrm{L})$ & 0,006 \\
\hline
\end{tabular}

Tabela 2. Concentração de cloro livre em amostras de alvejante e água de piscina.

\begin{tabular}{|c|c|c|}
\hline Amostra & $\boldsymbol{\mu T A D}(\mathbf{g} / \mathbf{L})$ & Titulação $\mathbf{( g / L )}$ \\
\hline Alvejante 1 & $15,6 \pm 10,8$ & $20,5 \pm 0,8$ \\
\hline Alvejante 2 & $15,0 \pm 7,05$ & $23,5 \pm 0,4$ \\
\hline Água de piscina 1 & $0,015 \pm 0,004$ & $0,016 \pm 0,001$ \\
\hline Água de piscina 2 & $<\mathrm{LOD}$ & 0,005 \\
\hline Água de piscina 3 & $<\mathrm{LOD}$ & 0,001 \\
\hline
\end{tabular}

\section{Conclusões}

Os $\mu$ TADs desenvolvidos são simples, de baixo custo e fáceis de serem utilizados em determinações rápidas de cloro livre em amostras simples

\section{Agradecimentos}

CNPq, Pibic, FAPESP, IQ-Unicamp.

\footnotetext{
1. Nilghaz, A., D.R. Ballerini, and W. Shen,.Biomicrofluidics, 7,2013,1. 2 Soares S. S., Arruda P. N., Lobón G. S., Scalize P. S.: Ciências Exatas e Tecnológicas, 37,2016, 119
} 